\title{
Prevalence of Inguinal Hernia in otherwise Healthy Males of 20 to 22 years of age
}

\author{
Maj ML Akin \\ MD
}

Assistant Professor of Surgery

Maj M Karakaya

MD

Assistant Professor of Surgery

\author{
Col A Batkin \\ MD \\ Professor of Surgery
}

\author{
Maj A Nogay \\ MD

\section{Assistant Professor of Surgery}

Gulhane Military Medical Academy, Haydarpasa Training Hospital, Department of General Surgery, Istanbul, Turkey

SUMMARY: Twenty-seven thousand four hundred and eight adult males between 20 and 22 years of age who were otherwise healthy were examined to detect inguinal hernias. Eight hundred and eighty-five (3.2\%) inguinal hernia cases were detected. These were $479(54.1 \%)$ right inguinal hernias, $351(39.7 \%)$ left inguinal hernias and $55(6.2 \%)$ bilateral inguinal hernias. One hundred and eighty-five $(\mathbf{2 0 . 9 \%})$ subjects reported first degree relatives and $147 \%$ (16.6\%) subjects reported second degree relatives with inguinal hernias.

It is concluded that these results may be a useful guide for future studies about the prevalence of inguinal hernias in the populations as a whole and suggest a familial predisposition.

\section{Introduction}

Abdominal wall hernia is one of the most common surgical diseases. Nine out of ten hernias occur through the anterior body wall and ninety percent of these ventral wall hernias are through the groin. This is an economically important condition as one in five males and one in fifty females will eventually have a hernia $(1,2)$.

The purpose of this study was to determine the prevalence of inguinal hernias in a specific group of people and to evaluate whether or not a familial distribution was present.

\section{Methods}

Twenty-seven thousand four hundred and eight adult males aged 20 to 22 years who were otherwise healthy were examined in 1995. These people were army servicemen who originated from different parts of Turkey and have come together for their military service.

Inguinal hernias were categorized as right, left and bilateral. Subjects with a history of undescended testes were excluded. The subjects were examined by four general surgeons and nine general practitioners. The questionable cases which were examined by general practitioners were evaluated again by general surgeons.

Those with inguinal hernias were interviewed to determine whether their first degree (parents, children and siblings) or second degree (grandparents, uncles, aunts, and cousins) relatives had inguinal hernias in order to determine a familial tendency.

McNemar's chi square test was used for statistical analysis. $P$ value of $<0.05$ was considered significant.

\section{Results}

Among the twenty-seven thousand four hundred and eight adult males aged 20 to 22 years who were examined, eight hundred and eighty-five (3.2\%) inguinal hernia cases were detected. These were $479(54.1 \%)$ right inguinal hernias, $351(39.7 \%)$ left inguinal hernias and $55(6.2 \%)$ bilateral inguinal hernias. The difference between right and left inguinal hernias was statistically significant $(\mathrm{P}<0.001)$. Among the 885 subjects who had inguinal hernias, 185 $(20.9 \%)$ subjects reported first degree relatives and 147 $(16.6 \%)$ subjects reported second degree relatives with inguinal hernias. The results of the study are summarised in Table 1.

\section{Discussion}

For several reasons exact figures on incidence and prevalence of abdominal hernias are unavailable. Many studies deal with special groups in different times. Patient populations are not stable and in a specific population the incidence of the disease may vary with the skills of the examiners. If a hernia is small, it may not be easily detected on examination. Some people do not seek medical 
Table 1

Prevalence and familial distribution of inguinal hernias

\begin{tabular}{lll} 
& n & \% \\
\hline Study group & 27,408 & $\mathbf{1 0 0}$ \\
Total number of inguinal hernias & 885 & 3.2 \\
\hline Right-sided hernia & 479 & 54.1 \\
Left-sided hernia & 351 & 39.7 \\
Bilateral hernia & 55 & 6.2 \\
\hline First degree relatives with inguinal hernia & 185 & 20.9 \\
Second degree relatives with inguinal hernia & 147 & 16.6 \\
\hline
\end{tabular}

help for their hernias because they do not consider it as a "disease"; and some people do not seek medical help because they simply do not have symptoms. Another factor is inguinal herniation may occur in any age group; a baby born with hernia may have none in his second year or a man may not develop hernia until age seventy.

Zimmermann and Anson (3) concluded that $5 \%$ of the total male adult population have abdominal hernias. The incidence of inguinal hernias varies depending on the type of population studied. In World War 1 British soldiers between the ages of 18 and 41 inguinal hernias varied from 1.7 to 5.6 percent; in men aged 16 to 30 years incidence was 0.6 percent and in men aged $40-50$ years it was 2.4 percent (4). Sir Arthur Keith (5) estimated the prevalence of inguinal hernias at 2.5 percent in 1924. The incidence in the British Army was $10 \%$ and in the U.S. Army was $2 \%$ in World War II (2), but these studies referred to all abdominal wall hernias. The incidence of inguinal hernia in male adults is higher in negroid peoples at 7.7 to 30 percent depending on the country studied (6-9) which is higher than in Europeans. We found the prevalence of inguinal hernias to be 3.2 percent in the study population.

Right-sided inguinal hernias $(55 \%)$ in adult European males are more frequent than left-sided (4). Nordback reported 44.1 percent right, 31.1 percent left and 24.8 percent incidence of bilateral inguinal hernias in 469 adult cases (10). el-Qaderi et al. (11) reported the incidence of right-sided, left-sided and bilateral inguinal hernias in both male and female adults of 1722 cases in northern Jordan as 60,35 and 5 percent respectively. In the present study we found 54.1 percent right-sided, 39.7 percent left-sided and 6.2 percent bilateral incidence of inguinal hernias which compromised with previous studies.
We found the prevalence of inguinal hernias in the study population with $20.9 \%$ of the subjects having an affectedz first degree relative and $16.6 \%$ having an affected second $\mathbb{Q}$. degree relative. These results suggest a familial predisposition to inguinal herniation.

Although these data which are derived from a largeses. population of young and healthy people are not: representative samples of the population we believe that $\stackrel{\oplus}{+}$ they may be a useful guide for the future studies about the prevalence of this economically important disease in whole population groups.

\section{Acknowledgments}

The authors would like to acknowledge Mr RJ Nichollsand Mr JS Jameson from St. Mark's Hospital, London, UKfor their generous help in preparing this manuscript.

\section{REFERENCES}

1. Morton JH. Abdominal wall hernias. In: Schwarts SI, Shires G, Spencer FC, eds. Principles of surgery. 5 th ed. New York: Mc Graw Hill, 1988; 1525-44.

2. GROSE WE. Abdominal wall hernia. In: Shackelford RT, Zuidema GD, eds. Surgery of the alimentary tract. 2nd ed. Philadelphia: WB Saunders, 1986; 105-8.

3. ZiMmerman IM, ANSON BJ. The anatomy and surgegy. of hernia. Baltimore: Williams \& Wilkins, 1953.

4. Devlin HB. Management of inguinal hernias. Lond㫣 Butterworth, 1988; 28.

5. KeITH A. On the origin and nature of hernia. $B r J$ S 1924; II: 455-75.

6. Belcher DW, Nyame DK, Wurapa FK. 遍 prevalence of inguinal hernia in adult Ghanaian malos. Trop Geogr Med 1978; 30: 39-43.

7. DORAN FSA. Three methods of repairing the deepo abdominal ring in men with primary indirect inguina $\mathbb{2}$ herniae. Br J Surg 1962; 49: 642-9.

8. Ashley GT. Hernia in East Africans - an anatomicaf analysis of 700 cases. East Afr Med $J$ 1954; 31: 315-9

9. YORDANOV YS, STOYANOV SK. The incidence of herniā̃ on the Island of Pemba. East Afr Med J 1969; 46: 867 8.

10. NORDBACK I. Side incidence of inguinal hernias. Ann Chir Gynaecol 1984, 73: 87-90.

11. el-QADERI S, Aligharaiben KI, Hani IB, Gassaimer G, AMMARI F. Hernia in northern Jordan. Trop Geogr? Med 1992; 44: 281-3. 